\title{
Fiscaoeconomia
}

E-ISSN: 2564-7504

2020, Volume 4, Issue 3, 613-627

Doi: $10.25295 /$ fsecon.762163

https://dergipark.org.tr/tr/pub/fsecon

Research Article

Please Cite As: Sezgin, A. \& Unutulmaz, S. (2020), "A Provincial Youth Population Analysis In

Terms of Time And Space: The Case of Turkey", Fiscaoeconomia, 4(3), 613-627.

\section{A Provincial Youth Population Analysis In Terms of Time And Space: The Case of Turkey}

\section{Aykut SEZGiN ${ }^{1}$, Sevim UNUTULMAZ ${ }^{2}$}

\begin{abstract}
The youth age period (0-14 age), which is one of the most important periods of human life, is also an important demographic indicator for countries. In this study, youth population, twenty five percent of the total population in Turkey, is examined from the perspective of time and space on provincial level. The coefficient of variation (CV) and Moran I index value was used to analyze the development of the young population parameter respectively over time and space. According to the CV results, the youth age population diversity increasess lightly between the provinces from 2007 to 2018 . In the $0-4$ age group shows high spatial pattern along the southeastern and eastern provinces. High spatial pattern is observed in 5-9 groups of central and northeast provinces. 04 and 5-9 age groups of these two regions are almost displaced by spatial pattern. All the findings shows that the young population in Turkey reveals a rapid change especially to 0-4 and 5-9 age groups. Population changes are often the subject of long-term analysis. This study emphasize that the population structure of a country can transform radically in the short term. This finding could lead policy makers on shorter term demographic solutions.
\end{abstract}

Article History:

Date submitted: 01.07.2020

Date accepted: 10.09.2020

Jel Codes:

$J 13, Q 56, C 21$

Keywords:

Youth Age Population,

Turkey,

Spatial Pattern

\footnotetext{
${ }^{1}$ Assist. Prof. Dr., Süleyman Demirel University, Faculty of Economics and Administrative Sciences, Department of Economics, aykutsezgin@sdu.edu.tr, 0000-0001-7039-8032.

${ }^{2}$ Süleyman Demirel University, Graduate School of Social Sciences, Department of Economics, sevimunutulmaz@ hotmail.com, 0000-0002-2286-9458.
} 


\section{Introduction}

Youth age covers the most important and remarkable process of human life, which consists of certain stages. This process is an important segment of the proportion of the population that are subject to investigation for Turkey (Baş and Çetin, 2017: 150). Youthage, as a period, refers to the period in which there is dependency to the parents. In this context, it symbolizes both a psycho-biological and a socio-historical category (Stoletov et al., 1979: 23).

Youth population gives important clues about the course of the total population. Some deviations in the youth age structure of the population are expected in the next 50 years. According to the United Nations population studies, it is estimated that the growth rate in developed countries will be negative to wards the end of 2050, and it will be positive in under developed countries. In the future, it is predicted that population growth will decrease in developed and developing countries (United Nations Population Division, 2001). Youth population constitutes an average of $30.2 \%$ of the world population. The top three countries with the highest proportion of youth population in total population are Niger, Uganda and Mali. Youth populationis 55.8\% in Niger, $55.1 \%$ in Uganda, $54.8 \%$ in Mali. Turkey is 97 th among the 167 countries in this regard. In Turkey, the youth population in the total population is twice the size than of Europe. The rate of elderly population in the total population is $1 / 3$. In Turkey, the number of the population between 0-14 ages is $22,920,422$. The province with the highest youth population rate by provinces is Şanlıurfa with $46.3 \%$. Then comes Şırnak with 43.9\% and Ağrı with 42.5\% (TUIK, 2018). These provinces are relatively economically under developed eastern and Southeastern cities of Turkey (Filiztekin and Çelik, 2010: 117). Tunceli, Edirne and Kırklareli are among the provinces with the lowest population between the ages of $0-14$ and the youth population in these provinces is $17.2 \%$ in Tunceli, $18.4 \%$ in Edirne and 19\% in Kırklareli (Sazak, 2004: 197).

The value obtained by dividing the dependent population value by the population of 15-64 age group, which is considered as the economically productive population, and multiplying this by 100 , is called the age dependency ratio. Dependency ratios are calculated as follows in three different ways (Şahin, 2018: 133):

- $\quad$ Age (General) Dependency Rate: [(0-14 Age Group Population + 65 Age and Above Population) / Annual Total Birth] x Population

- $\quad$ Youth (Young) Dependency Rate: [0-14 Age Group Population / 15-64 Age Group Population] x Population

- $\quad$ Aging (Elderly) Dependency Rate: [65 and Over Population / 15-64 Age Group Population] x Population

As the population between $0-14$ years is high in countries where child birth rate is high, the rate of youth dependency and the number of young dependent people is high. Countries with a high dependency rate among population may negatively be affected in their economies (see Table 1). 
Table 1. Age dependency rates in the World (\%)

\begin{tabular}{|c|c|c|c|} 
& General & Young & Elderly \\
\hline World & 52 & 40 & 13 \\
\hline Africa & 79 & 73 & 6 \\
\hline Asia & 47 & 36 & 11 \\
\hline Europe & 49 & 24 & 26 \\
\hline $\begin{array}{c}\text { Central and South } \\
\text { America }\end{array}$ & 52 & 41 & 11 \\
\hline North America & 51 & 29 & 22 \\
\hline Oceania & 55 & 37 & 18 \\
\hline
\end{tabular}

Source: Şahin, 2018.

Considering the world population, the dependency ratio in the total population is $52 \%$. When this ratio is analyzed in terms of continents, it is higher in Africa compared to other continents. Besides, the fact that the share of the elderly population in the total population is low indicates that the dependency rate in high age values is low. The continent with the lowest dependency rate is Europe. The value of Turkey in this regard are shown in Table 2.

Table 2. Population realizations by age and its projections in Turkey (as percentage)

\begin{tabular}{|c|c|c|c|c|c|c|c|c|}
\hline Age & 1980 & 1990 & 2000 & 2010 & 2020 & 2030 & 2040 & 2050 \\
\hline $0-14$ & 40.4 & 35.7 & 30.5 & 26.2 & 23.1 & 20.4 & 18.5 & 17.5 \\
\hline $15-64$ & 55.0 & 60.2 & 64.4 & 67.9 & 69.3 & 68.8 & 66.9 & 64.1 \\
\hline $65+$ & 4.6 & 4.0 & 5.2 & 5.9 & 7.6 & 10.8 & 14.6 & 18.4 \\
\hline
\end{tabular}

Source: TUIK, Address Based Population Registration System Statistics.

According to Turkish Statistical Institute (TUIK), the rate of child dependency is $40.4 \%$ in 1980 , $35.7 \%$ in $1990,30.5 \%$ in 2000 and $26.1 \%$ in 2010 . According to the estimates with in the period, youth dependency rates are expected to be $23.1 \%$ in $2020,20.4 \%$ in $2030,18.5 \%$ in 2040 and $15.5 \%$ in 2050 . As seen in the table, the relative dominance of the 15-64 age group will begin to decline by 2020 due to the growing elderly population. In addition to this, Ercan (2007) states that because 0-19 age peaked in 2000, Turkey will not have a "young" population any more. It will take some time to get used to this collective and political mentality. In addition, the demographic opportunity window closes in 2040. Likewise, 15-64 age group has started to decrease in number. Therefore, the population census years of 2000 and 2040 are two important turning points in Turkey's demography. The population between the ages of 0 and 19 reached a peak of 27.7 million in 2000. Despite the support provided by immigrants from outside the villages, the number gradually decreases after these dates. At this stage, the education demand of the Turkish demography and the size of the potential work force can be estimated with increasing accuracy (Ercan, 2007: 9).

Traditional aging measurement is based on chronological age. It was assumed that a person aged 60 in 1900 and a person aged 60 in 2000 were old as same because they lived the same number of years. However, is it possible to say that both are aging at the same rate? Afterall, people living 60 years in 2000 will, on average, have much longer life. Population aging is not just about there are older people in the community. It is also about people who live longer lives (Lutz, 2008: 716). As of 2015, the global population of 60 and older has increased by $48 \%$ since 2000 and reached 901 million world wide. It is estimated that this figure will be 1.4 billion in 2030 and 2.1 billion in 2050 and will constitute $16 \%$ and $22 \%$ of the total population, 
respectively. Although the share of projections seems to be decreasing, this large group of young people is about healthy and productive individuals in society, how well governments and civil societies invest in social, economic and political institutions that will meet the current needs of young people (Assaad and Roudi-Fahimi, 2007: 1).

As all these figures indicate, national or supra-national comparisons come to the fore in youth population analysis. Young population information is often used by policy makers in the formulation of national policies. Sub-national youth population data are requested by national policy makers either to see only change over time or distribution within the country. Studies that evaluate time and space dimensions together are an important source of information for regional policy makers.

\section{Literature Review}

For population statistics researchers, the population is usually defined by the regions they occupy rather than ethnic, national, cultural, genetic or demographic differences, and therefore determined by their political or administrative areas. Different classification options and methods have been developed for each different purpose. In classifications made for age, the life time span is usually divided into five-year periods. Five-year periods are the most preferred form of age classification in the formation of population pyramids (Macbeth and Collinson, 2002: 44).

Youth population has been defined in different ways. According to the OECD, the youth (or young) population is defined as the number of people under the age of 15 . The youth population ratio is obtained by dividing the population under the age of 15 by the total population. Youth dependency ratio is the ratio of the population under the age of 15 to the population that is obliged to meet the daily needs of this population. The group, which is obliged by taking care of the population under the age of 15 , is generally taken between the ages of 15-65 (OECD, 2019; TUIK, 2019). Sources such as World Bank, United Nations and US Cencus Breau, mean while, states under the age of 18 as the youth population (US CENSUS, 2011; World Bank, 2019; UNCTAD, 2018). Also there is an ambiguity between the concepts of youth population and child population. Innon-scientific studies, the youth population is often referred to as the child population.

To analyze the course of age distribution of population over time (as a time series), it is necessary to look at fertility and mortality rates. The main factor affecting the age structure of a country is fertility and mortality rates in that country. If fertility and mortality rates and structures are known in certain time periods, it is also possible to comment on how the age structure will change in the future (Lopez, 1961; Casetti, 1977; Tung, 1984).

Assuming that fertility and mortality do not change in the long term, stable population theory is a model that is not seen in real life but provides theoretical implications. The same fertilty and mortality is an indication that age composition will not change in the long run. This fixed aged distribution is considered stable age distribution (Espenshade et al., 1982: 132).

The population structure of space has a direct effect on many socio-economic variables of that space. An important question that stands out here is what will be the unit of space where the population is analyzed. In many disciplines working with geography, the spatial structure of the geography of interest and how it is divided are important. The space of interest may have regular shapes, sometimes it may have irregular shapes. While analyzing the spaces with regular shapes, the frequency distributions of the data of the space analyzed are regular, and the opposite situation may arise in spaces with irregular shapes (Boots, 1977: 380).

In order to give accurate results in the frequency distribution of the population data in the analyzed regions, methods such as fragmentation indices and patches are used in ecology. Similar methods can be used in discussions about to what extend the regional studies would 
be in social sciences. An example of this is the preference of the different levels of the NUTS (The Nomancelature of Territoral Units for Statistics) (Turner et al., 2001). On the study in this context, NUTS3 comparisons (based on province) were preferred which is the smallest regional representative of the NUTS classifications. Thus, it is aimed that the geography and the geographical data will display a relatively homogeneous structure.

One of the most effective ways to analyze the distribution of data in space is using spatial autocorrelation analysis. Spatial autocorrelation is when the data of the spatial areas close to each other are more related than the distant ones. In other words, each data has a characteristic distance that is correlated with it. As Tobler (1970) put it, 'Everything is related to everything else, but nearthings are more related than distant things'. Geographers often tend to find a spatial pattern by looking at the data. If there is spatial autocorrelation, it objectively reveals the spatial pattern. Indicates if the spatial pattern, if any, is random or unusual. The basic logic in autocorrelation is to show how space data (attribute) relate to proximity or distance. Moran's I-statistics are especially useful where the spatial sampling scale is in the context of a larger spatial pattern. This is actually clear in the definition of "spatial autocorrelation" (Anselin, 1980; Epperson and Li, 1996).

As can be seen, youth population studies and projections in the literature generally examine the change of population either only in time or only in space. In this context, Turkey's youth population structure in the article is analyzed in both time and space dimensions.

\section{Methodology}

The coefficient of variation measures the variability of a series of numbers independently of the unit of measurement used for these numbers. In order to do so, the CV eliminates the unit of measurement of the standard deviation of a series of numbers by dividing it by the mean of these numbers. The CV can be used to compare distributions obtained with different units, such as, for example, the variability of the weights of newborns (measured in grams) with the size of adults (measured in centimeters). The CV is meaningful only for measurements with a real zero (i.e., "ratio scales") because the mean is meaningful (i.e., unique) only for these scales (Abdi, 2010: 1). CV approach was used to analyze the development of the youth population parameter over time, i.e. the time dimension. Also it is often used to measure differences in regional development and imbalanced development (Wang et al., 2013: 1063). In this study, the CV measurement was used to analyze the fluctuations in the NUTS 3 level (based on provinces) in the observed period of the youth population in Turkey.

$\mathrm{CV}$ is very useful when you want to compare the results obtained from two different surveys or tests with different measurements or values. For example, if the results of two tests with different scoring mechanisms are compared, it is possible to say that if sample $A$ has a value of $12 \%$ CV and sample B has a value of $25 \%$ CV, sample B varies more than the average (Chen et al., 2019: 852).

The CV value is calculated as follows:

$$
C V=\frac{1}{\bar{Y}}\left[\frac{1}{n} \sum_{i=1}^{n}\left(\mathrm{Y}_{i}-\overline{\mathrm{Y}}\right)^{2}\right]^{\frac{1}{2}}
$$

The parameters in the equation can be expressed as follows with their equivalents in this study: CV variation coefficient, $\bar{Y}$ is the average value of the youth population, $\mathrm{n}$ is the number of provinces and $Y_{i}$ is the youth population value in the province. As the value of $C V$ increases, the difference between youth population values at the provincial level increases. In a finite non-negative example, the CV can take a value between 0 and $V(N-1)$ (Reed et al., 2002; Abdi, 2010). 
It should be noted that the CV has nothing to do with geographic location and only refers to the degree of distribution. In this context, Moran's I index value, which has become a traditional method, has been used to measure the distribution of the youth population parameter in space. Moran's globally accepted I index is used to calculates partial autocorrelation, that is, the degree of difference of values observed in neighboring regions (Moran, 1948). Therefore, in this study, the Moran's I index was calculated to measure the regional imbalance and spatial autocorrelation of the youth population distribution.

The calculation method of I index of Moran is given in Formula X:

$$
I=\frac{N}{\sum_{i} \sum_{j} w_{i j}} \frac{\sum_{i} \sum_{j} w_{i j}\left(X_{i}-\bar{X}\right)\left(X_{j}-\bar{X}\right)}{\sum_{i}\left(X_{i}-\bar{X}\right)^{2}}
$$

In the formula, I represents the index value, $N$ is the number of observations, $w_{i j}$ is the standardized weight matrix, and $X$ is the corresponding variable. The weight matrix is the neighborhood matrix used to calculate the I index (Shortridge, 2007; Ward and Gleditsch, 2008).

In this study, Quenn contiguity is used as the neighborhood method. So if region $\mathrm{i}$ is adjacent to region $\mathrm{j}$ from any direction, then $w_{i j}=1$; other wise $w_{i j}=0$. If there is a neighborly relationship between the two regions, the value will be 1, if not, it will be 0 (Anselin, 1988).

Moran's I index values are in the range $[-1,1]$. If the index value is greater than zero, it can be said that there is a positive spatial autocorrelation (clustering of similar values). In other words, relatively high or low youth population ratio stend to cluster / resemble significantly in near by regions. If the index value is less than zero, there is a negative spatial autocorrelation (clustering of similar values). In other words, there is a difference between the region in question and its neighbors in terms of youth population rates. If the index value is zero, it means that there is no spatial autocorrelation relationship (perfect randomness). In this case, there is a random spatial distribution among the youth population rates of the regions (Çetin, 2012: 68-71).

The $z$ test is used to calculate the significance level of the Moran's I index. The presence of positive or negative spatial autocorrelation or the absence of autocorrelation is interpreted by looking at the $z$ values for the desired confidence interval (Cliff and Ord, 1981).

$$
z_{t}=\frac{1-E\left(I_{t}\right)}{\sqrt{\operatorname{VAR}\left(I_{t}\right)}}
$$

Moran's scatterplot is a exploratory spatial data analysis (ESDA) tool developed by Anselin (1996) to evaluate local spatial association models. This bivariate distribution chart places the unit values (xi) on the horizontal axis and the spatial delay (lagi) on the vertical axis for the same variable. Spatial delay is the spatially weighted average of values in neighboring units and is calculated as follows (Fischer and Getis, 2010: 290-291):

$$
\text { lagi }=\frac{\sum_{j=1}^{n} w_{i j} x_{j}}{\sum_{j=1}^{n} w_{i j}}
$$

On Figure 1, the axes of the graph are drawn with the mean values of xi and lagi respectively. The four quadrants in the area divide the spatial composition into four components. The first letter in the dial labels indicates that the value of xi is higher $(\mathrm{H})$ or lower $(\mathrm{L})$ than the average of all values. Therefore, the second letter in the dial labels is higher $(H)$ or lower $(L)$ than the average of all spatial delays. The dials labeled ' $\mathrm{HH}$ ' and ' $\mathrm{LL}$ ' represent the cluster of high and low values, respectively. The remaining dials contain units that are negatively related to their 
neighborsand can be considered spatial outliers. In this context, the Moran's scatter plot visually presents spatial clusters and their patterns.

Figure 1. Spatial Cluster Pattern

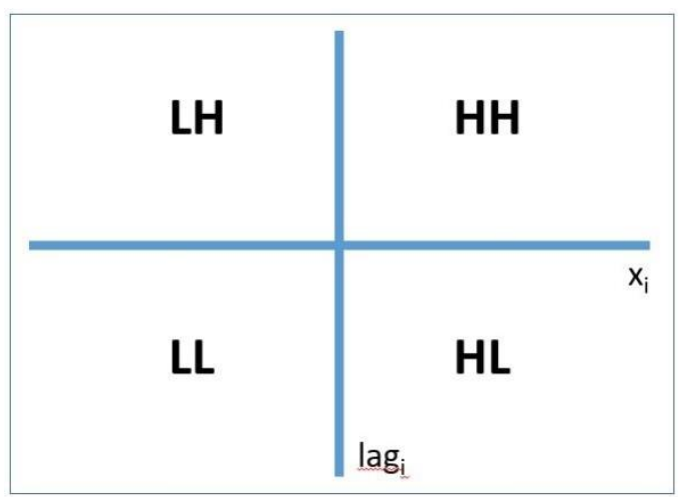

In Anselin (1995), LISA (Local Indicators of Spatial Association) indicators distinguish the global spatial indicators calculated by the Moran's I indices to take into account the contribution of each observation. The Moran's scatter plot above is also the most preferred among these indicators (Anselin, 1996; Ranta et al., 1997; Kelejian and Prucha, 2001; Koenig, 2002).

In order to analyze and interpret the spatial clustering and autocorrelation data together, the statistical value and significance value of the Moran's I index and the label of the corresponding dial of the Moran's distribution graph are found. The value of the Moran's I index between +1 and -1 is interpreted for spatial autocorrelation. Then, by looking at the Moran scatter plot for each variable, it is determined which of the four quadrants is valid.

\section{Implications And Empirical Results}

The first census in the Republic of Turkey has been carried out in 1927, the next census were carried out every five years from 1935 til 1990. The census conducted in 2000 is the last census conducted in the traditional sense. In 2006, the Address Based Population Registration System (ABPRS) was launched. After switching to this system, population data is up dated and published by Turkey's Statistics Institute since 2007. The main purpose of this system is to keep the population information of the settlement up-to-date and to regularly monitor the population movements. The legal basis of the system is the Population Services Law No. 5490, enacted on April 25, 2006 (TUIK, 2019).

In ABPRS, the definition of youth population rate is used between the ages of $0-14$ in accordance with the literature. The 0-14 age group is also taken as the basis for calculating youth dependency rates. In the study in this context, TUIK ABPRS data are being used while examining Turkey's youth population ratios. In the context of the data obtained from TUIK between the ages of 0-14, it was evaluated in three sub-categories as 0-4, 5-9 and 10-14 age groups.

From 2007 to 2018 the total population in Turkey increased from 70,586,256 to 82,003,882. This increase has followed an on going trend of increase, as seen in Figure 2. Youth population figures increased from 18,542,391 to 19,184,329. The youth population figure decreased some what from 2009 to 2013, and then started to rise again. In order to examine this period of fluctation, which takes place periodically, the group between the ages of 0-14 should be examined separately for $0-4,5-9$ and $10-14$ age groups. 
Figure 2. Total and Youth Population According to ABPRS in Turkey

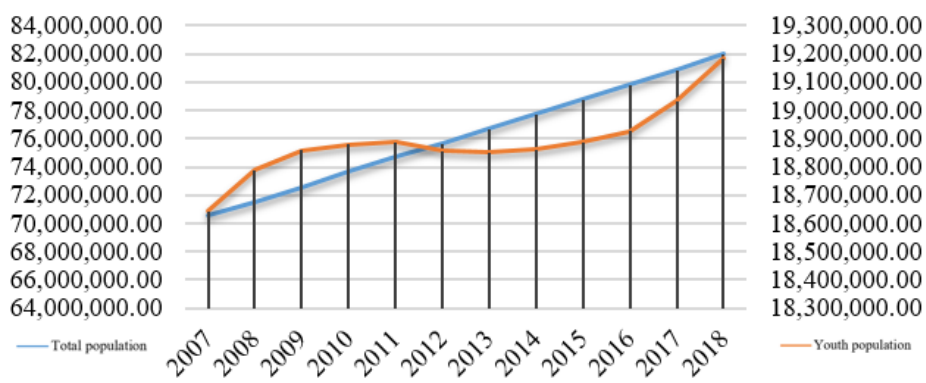

According to ABPRS, the population in the 0-4 age group among the 0-14 age group has been increasing continuously since 2007 . The population in the 5-9 age group decreases between 2007-2011 and increases between 2011-2018. The population of 10-14 age group shows an increase between 2007-2011, a decrease between 2011-2016 and an increase after 2016. The main reason for the decrease in the total youth population between 2009-2013 seems to be the decrease of the population of 5-9 age group until 2011 and 10-14 age group after 2011. In this period, a slow down was experienced in the population increase of the 0-4 age group. ConsideringTurkey's total population, these increases and decreases proportionally correspond to very low levels. Yet the increase in the youth population (0-14) after 2013 should be considered bearing in mind that the external migrations Turkey has experienced during this period (see Figure 3).

\section{Figure 3. 0-14 Age Population According to Sub-Categories}

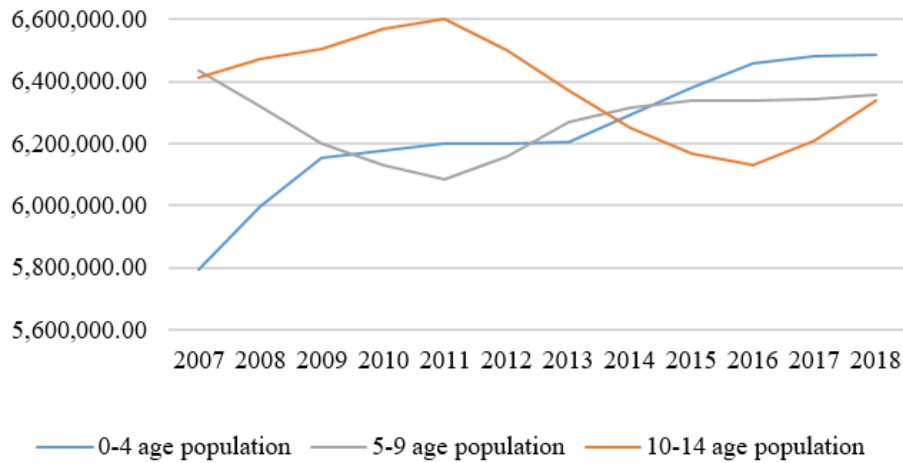

CV of youth population was calculated to analyze the development of the youth population parameter over time. The higher the CV value, the higher the difference in the number of young population on the NUTS3 scale (province-based). In Figure 4, CV values are given together with the youth population and its sub-categories. According to the figure, the values of the CV of youth population seen on the right axis and the CV of lower age group classes seen on the left axis go from 2007 to 2018, although some years are exceptions, they follow a horizontal course. The striking point here is the CV difference between youth population and lower age group values. Youth population has about $26 \% \mathrm{CV}$, while lower age groups have CV values between $1 \%$ and $5 \%$. Therefore, the youth population is more diverse among the provinces. The lower age groups show relatively less variety. 
Figure 4. Coefficient of Variation of Youth Population of Turkey

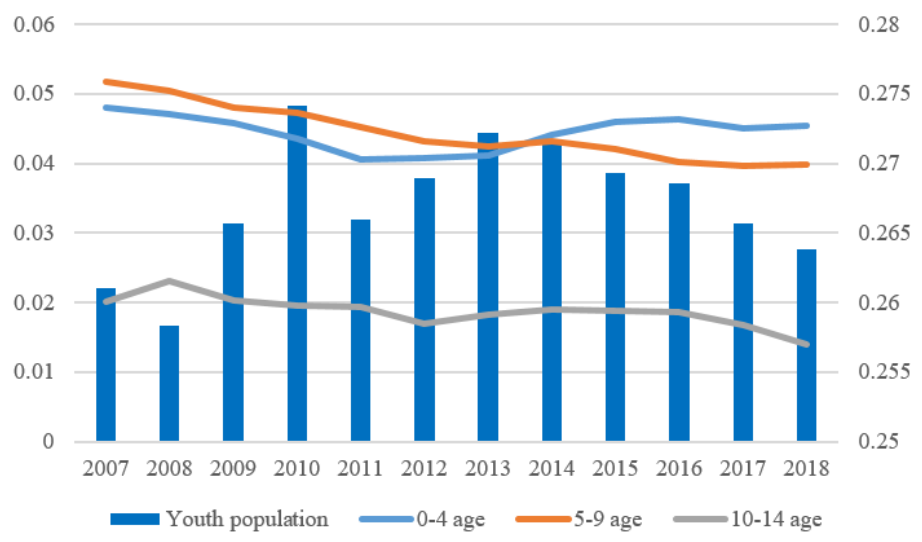

Spatial autocorrelation and spatial cluster results calculated on the basis of provinces between 2007 and 2018 using ABPRS youth population ratio data are shown in Table 3 . The youth population of each province in Turkey is divided by the total population of that province for spatial analysis. In this study, all Moran's I values were negative. In this case, dissimilar clustering occurs on a provincial basis for all years and all age groups. The $p$-values for all variables are below 0.05 . Therefore, dissimilar clustering status is meaningful for all variables and there is a spatial autocorrelation on the basis of province. As mentioned in the methodology, the next stage of the analysis is to obtain Moran's scatter plots over the ratios of the relevant youth population class of each province to the total population of that province. Thus, significant hotspot points will be determined at the provincial level.

Table 3. Moran's Test Results

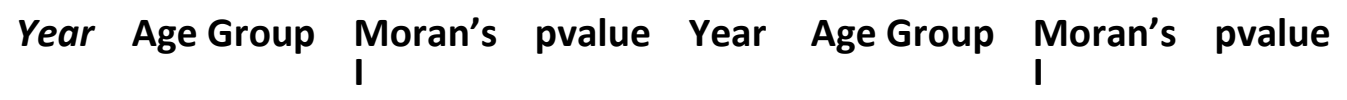

\begin{tabular}{|c|c|c|c|c|c|c|c|}
\hline \multirow[t]{4}{*}{2007} & $\% 0-4$ & -0.058 & 0.000 & \multirow[t]{4}{*}{2013} & $\% 0-4$ & -0.058 & 0.000 \\
\hline & $\% 5-9$ & -0.088 & 0.000 & & $\% 5-9$ & -0.053 & 0.000 \\
\hline & \%10-14 & -0.121 & 0.000 & & \%10-14 & -0.107 & 0.000 \\
\hline & $\begin{array}{l}\text { \% Youth } \\
\text { Population }\end{array}$ & -0.252 & 0.000 & & $\begin{array}{l}\text { \% Youth } \\
\text { Population }\end{array}$ & -0.220 & 0.000 \\
\hline \multirow[t]{4}{*}{2008} & $\% 0-4$ & -0.052 & 0.000 & \multirow[t]{4}{*}{2014} & $\% 0-4$ & -0.070 & 0.000 \\
\hline & $\% 5-9$ & -0.083 & 0.000 & & $\% 5-9$ & -0.052 & 0.000 \\
\hline & \%10-14 & -0.165 & 0.000 & & \%10-14 & -0.153 & 0.000 \\
\hline & $\begin{array}{l}\text { \% Youth } \\
\text { Population }\end{array}$ & -0.242 & 0.000 & & $\begin{array}{l}\text { \% Youth } \\
\text { Population }\end{array}$ & -0.213 & 0.000 \\
\hline \multirow[t]{4}{*}{2009} & $\% 0-4$ & -0.053 & 0.000 & \multirow[t]{4}{*}{2015} & $\% 0-4$ & -0.066 & 0.000 \\
\hline & $\% 5-9$ & -0.072 & 0.000 & & $\% 5-9$ & -0.044 & 0.000 \\
\hline & \%10-14 & -0.134 & 0.000 & & \%10-14 & -0.149 & 0.000 \\
\hline & $\begin{array}{l}\text { \% Youth } \\
\text { Population }\end{array}$ & -0.240 & 0.000 & & $\begin{array}{l}\text { \% Youth } \\
\text { Population }\end{array}$ & -0.210 & 0.000 \\
\hline \multirow[t]{3}{*}{2010} & $\% 0-4$ & -0.050 & 0.000 & \multirow[t]{3}{*}{2016} & $\% 0-4$ & -0.060 & 0.000 \\
\hline & $\% 5-9$ & -0.067 & 0.000 & & $\% 5-9$ & -0.034 & 0.005 \\
\hline & \%10-14 & -0.112 & 0.000 & & \%10-14 & -0.148 & 0.000 \\
\hline
\end{tabular}




\begin{tabular}{|c|c|c|c|c|c|c|c|}
\hline & $\begin{array}{l}\text { \% Youth } \\
\text { Population }\end{array}$ & -0.239 & 0.000 & & $\begin{array}{l}\text { \% Youth } \\
\text { Population }\end{array}$ & -0.207 & 0.000 \\
\hline \multirow[t]{4}{*}{2011} & $\% 0-4$ & -0.043 & 0.000 & \multirow[t]{4}{*}{2017} & $\% 0-4$ & -0.071 & 0.000 \\
\hline & $\% 5-9$ & -0.066 & 0.000 & & $\% 5-9$ & -0.037 & 0.002 \\
\hline & \%10-14 & -0.091 & 0.000 & & \%10-14 & -0.107 & 0.000 \\
\hline & $\begin{array}{l}\text { \% Youth } \\
\text { Population }\end{array}$ & -0.226 & 0.000 & & $\begin{array}{l}\text { \% Youth } \\
\text { Population }\end{array}$ & -0.203 & 0.000 \\
\hline \multirow[t]{4}{*}{2012} & $\% 0-4$ & -0.046 & 0.000 & \multirow[t]{4}{*}{2018} & $\% 0-4$ & -0.083 & 0.000 \\
\hline & $\% 5-9$ & -0.057 & 0.000 & & $\% 5-9$ & -0.061 & 0.000 \\
\hline & $\% 10-14$ & -0.041 & 0.000 & & $\% 10-4$ & -0.061 & 0.000 \\
\hline & $\begin{array}{l}\text { \% Youth } \\
\text { Population }\end{array}$ & -0.222 & 0.000 & & $\begin{array}{l}\text { \% Youth } \\
\text { Population }\end{array}$ & -0.191 & 0.000 \\
\hline
\end{tabular}

In Figure 5, clustering results of Moran's scatter plots belonging to youth population and other sub-categories are given respectively. ${ }^{3}$ The provinces shown in red in turkey map refers to $\mathrm{HH}$ (high-high) cluster. These province shave a high population rate compared to other provinces with their neighbors in red. Provinces seen in green indicate LL (low-low) cluster. These provinces have a low population rate compared to other provinces with their green neighbors. Pink-colored HL (high-low) provinces refer to high-population provinces with low population neighbors, and yellow-colored LH (low-high) provinces, on the contrary, low-population provinces with high population neighbors. Therefore, HL and LHs shows patial outliers.

${ }^{3}$ QGIS 3.10.2 geographic information system program was used for mapping operations. 
Figure 5. Clustering of Youth Population and Sub-Categories

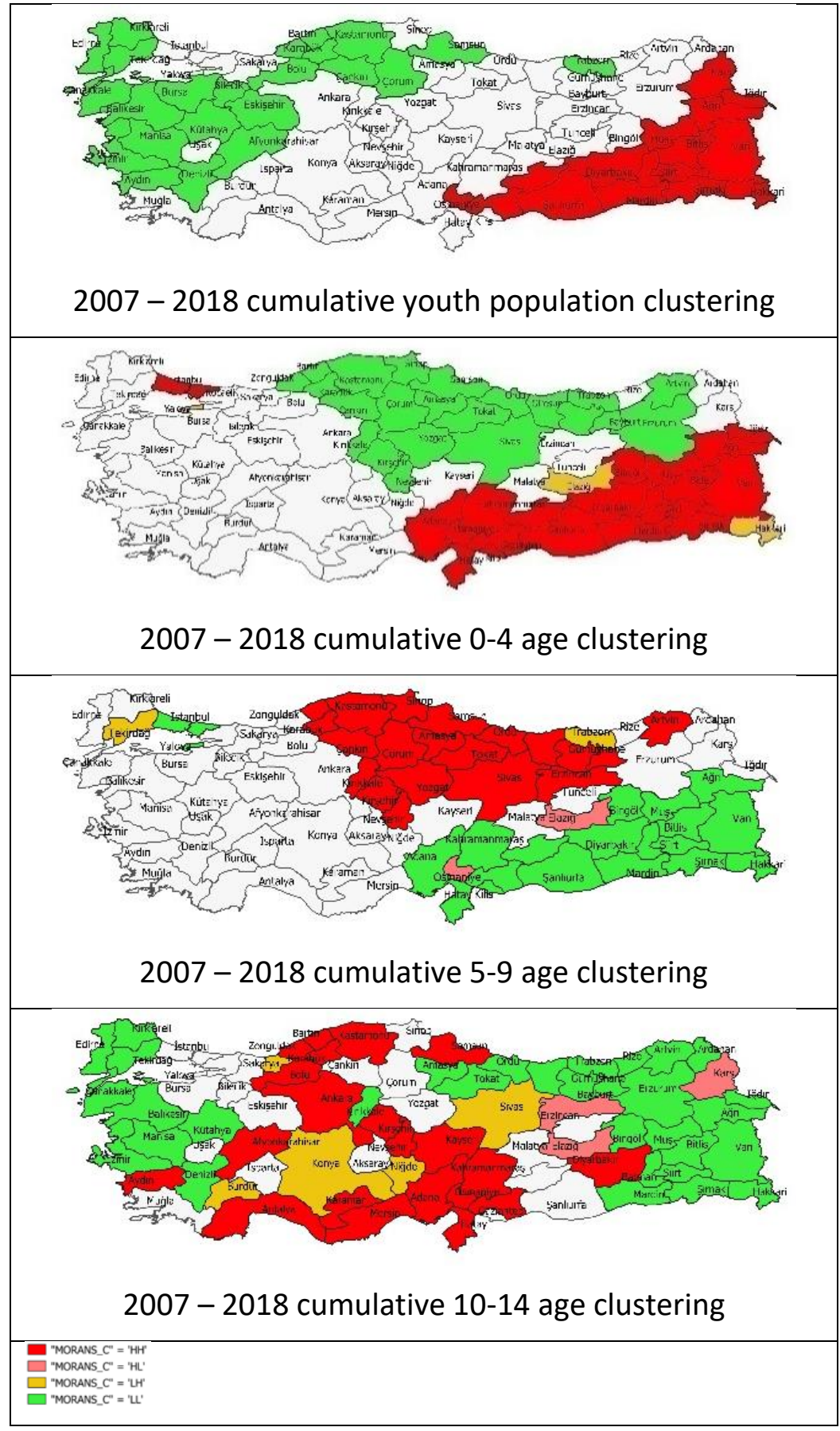

\section{Conclusions}

The population structure and future projections of a space shape the social and economic structure of the space as well as its demographic structure. Youth age is one of the population indicators that can be used to determine how the population will follow in the designated region in the future. Research shows that regions with high youth dependency rates are also regions with high population growth rates. Youth dependency ratio's being relatively high in the economically under developed regions in the world and in Turkey confirmes the negative correlation between the rate of population growth and economic development in this sense. Spatial pattern information, which will be found by looking at the youth age population 
information that gives clues about the future of the population, will be an important data source for policy makers in determining current and future policies. In this context, youth age distribution of the population in Turkey is being examined this study with in the framework of province, time and space base which locally make up policy making in Turkey.

According to the $\mathrm{CV}$ results used for the time dimension of the analysis, the youth age population diversity increases slightly between the provinces from 2007 to 2018 . The diversity is lower in the lower age groups (0-4, 5-9 and 10-14). Turkey ABPRS fluctuations in population figures also affects CV out comes. Therefore, rather than the fluctuations experienced over the years, the focus has been on the determination that diversity among provinces differ in different age groups.

The spatial pattern of the provincial diversity in question enables the size of the analysis to be determined. The fact that the Moran's I test results for all years yield different dissimilar clustering levels with different index values in each age group supports the diversity difference of the age groups obtained according to the CV results.

Mapping of Moran's scatter plot results showing spatial pattern was made separately for youth age population and lower age groups. The maps obtained for each year are presented cumulatively with the layers of each year over lapping for easier visual interpretation. Youth popultion has been found to be higher for the cluster in the eastern provinces and southeastern Turkey. The youth population in these provinces, shown in red on the map, are high together. The provinces in green in the west and north are the provinces where low clustering is detected and they have low young population together.

This structure of young population differs in lower age groups. While the western provinces lose their low characteristics together in the 0-4 and 5-9 age groups, in some provinces they regain it in the 10-14 age group. The southeast and eastern provinces show their high characteristics together only in the 0-4 age group. In the 5-9 age group, the high feature together shifts to the middle and northeastern regions, while in the 10-14 age group it shows a diffuse structure.

To sum up the 0-4 age group, where there is high population growth rate in Turkey, exhibits high spatial pattern along the southeastern and eastern provinces. High spatial pattern is observed in 5-9 groups of central and northeast provinces. The 0-4 and 5-9 age groups are almost displaced by spatial pattern. Some provinces between these two regions also form $\mathrm{HL}$ and LH (outliers) crossing lines in the 0-4 and 5-9 age groups. These two dominant patterns found in the results of the analysis may make some determinations important to policy makers. Very high population growth rates in provinces with high pattern in the 0-4 age group can create socio-economic disadvantages. 5-9 age group for the primary school age group that started in Turkey, together with a high degree pattern of this group can be used as pilot training policies in the provinces.

The scattered spatial pattern of 10-14 age group shows that when HL and LH are removed, there are no regional clusterings as other age groups. This also supports the low CV of this age group. The diversity among provinces is lower in this age group.

All these findings reveal that young population in Turkey shows a rapid change in time in spatial terms, especially for the 0-4 and 5-9 age groups. In the years, Turkey has undergone rapid transformation and change from a socioeconomic perspective. Spatial analysis of youth population changes when read in conjunction with the figures, a conversion is determined in the demographic structure of Turkey. This study, which only takes the provincial spatial picture of youth population, will shed light on other studies that search this conversion with its causes and all outcomes. 
This change and the spatial pattern of the young population on a provincial basis will ensure that the demographic decisions to be taken by the provinces will yield more effective results when taken together with the provinces that are close to them.

People may not notice the change occurring in the demographic structure in the short term. Because they are already in change. This determination is also valid for policy makers. By revealing the change in the demographic structure, policy makers will consider this change in all their decisions that are affected by the demographic structure and affect the demographic structure. This study also will guide local policy makers with its provincial scale.

The beginning of ABPRS information from 2007 hinders retrospective analysis. In addition, it can be thought that the migration movements experienced in the said period also affected the result of the study. The study aims to open the door to a more comprehensive result by strengthening it with new spatial analyzes to be made at NUTS1 and NUTS2 and even at the district levels in Turkey.

Funding: This research received no external funding

Acknowledgments: We appreciate Prof. Murat Ali Dulupçu for the guidance and support on the study design.

Conflicts of Interest: The authors declare no conflict of interest.

\section{References}

Abdi, H. (2010), "Coefficient of Variation”. Encyclopedia of Research Design, 1, 169-171.

Assaad, R., and Roudi-Fahimi, F. (2007). Youth in the Middle Eastand North Africa: Demographic Opportunity or Challenge?. Washington, DC: Population Reference Bureau.

Anselin, L. (1980), "Estimation Methods for Spatial Autoregressive Structures". Estimation Methods for Spatial Autoregressive Structures, 8.

Anselin, L. (1988), Spatial Econometrics: Methods and Models. Studies in Operational Regional Science. Kluwer Academic Publishers.

Anselin, L. (1995), "Local indicators of spatial association-LISA". Geographical analysis, 27(2), 93-115.

Anselin, L. (1996), "The Moran Scatterplot as an ESDA Tool to Assess Local Instability in Spatial". Spatial Analytical, 4, 111.

Baş, H., and Çetin, B. I. (2017), "Bir Sosyal Bilimler Belediyecilik Uygulaması Olarak İstanbul Esenler Belediyesi Gençlik Merkezi Örneği”. Abant Izzet Baysal Üniversitesi Sosyal Bilimler Enstitüsü Dergisi, 17(1), 149-175.

Baş, H. (2017), "Türkiye'de Genç Nüfus: Sorunlar ve Politikalar". Journal of Suleyman Demirel University Institute of Social Sciences, 27(2).

Boots, B. N. (1977), "Contact Number Properties in the Study of Cellular Networks". Geographical Analysis, 9(4), 379-387. 
Casetti, E. (1977), "Economic Growth and The Population Explosion: Simulation Experiments Using a Growth Model With Population Endogenous". The Journal of Development Studies, 13(3), 238-261.

Chen, Y., Bouferguene, A., Shen, Y., and Al-Hussein, M. (2019). “Difference Analysis of Regional Population Ageing From Temporal and Spatial Perspectives: A Case Study in China". Regional Studies, 53(6), 849-860.

Cliff, A. D., and Ord, J. K. (1981), Spatial Processes: Models and Applications. Taylor and Francis.

Çetin, D. (2012), Exports and Clusters: A Spatial Econometric Analysis on Ankara and Istanbul OIZs. Orta Doğu Teknik Üniversitesi, Unpublished PhD thesis, Ankara.

Epperson, B. K., and Li, T. (1996), "Measurement of Genetic Structure With in Populations Using Moran's Spatial Autocorrelation Statistics". Proceedings of the National Academy of Sciences, 93(19), 10528-10532.

Espenshade, T. J., Bouvier, L. F., and Arthur, W. B. (1982), "Immigration and the Stable Population Model”. Demography, 19(1), 125-133.

Filiztekin, A., and Çelik, M. A. (2010), "Türkiye'de Bölgesel Gelir Eşitsizliği (Regional Income Inequality in Turkey)". Megaron, 5(3), 116-127.

Fischer, M. M., and Getis, A. (Eds.). (2009), Handbook of applied Spatial Analysis: Software Tools, Methods and Applications. Springer Science and Business Media.

Ercan, H. (2007). Youth employment in Turkey. International Labour Office.

Kelejian, H. H., and Prucha, I. R. (2001), "On the Asymptotic Distribution of The Moran I Test Statistic with Applications". Journal of Econometrics, 104(2), 219-257.

Koenig, W. D. (2002), "Global Patterns of Environmental Synchrony and The Moran Effect”. Ecography, 25(3), 283-288.

Lutz, W., Sanderson, W., and Scherbov, S. (2008), "The Coming Acceleration of Global Population Ageing". Nature, 451(7179), 716-719.

Lopez, R. S. (1961). The Crossroads With in The Wall.

Macbeth, H., and Collinson, P. (ed). (2002), Human Population Dynamics: Cross-Disciplinary Perspectives (Vol. 14). Cambridge University Press.

Moran, P. A. P. (1948), "The Interpretation of Statistical Maps". Journal of the Royal Statistical Society Series B (Methodological), 10(2), 243-251.

OECD, (2019), Young Population (Indicator).doi: 10.1787/3d774f19-en (Accessed on 19 June 2019)

Ranta, E., Kaitala, V., Lindström, J., and Helle, E. (1997), "The Moran Effect and Synchrony In Population Dynamics". Oikos, 136-142.

Reed, G. F., Lynn, F., and Meade, B. D. (2002), "Use of Coefficient of Variation in Assessing Variability of Quantitative Assays". Clin. Diagn. Lab. Immunol, 9(6), 1235-1239. 
Sazak, Ş. (2016), "Türkiye'de Bölgelere Göre Nüfusun Yaş Gruplarına Dağılımı”. Trakya Üniversitesi Fen Bilimleri Dergisi, 5(2), 187-198.

Shortridge, A. (2007), "Practical Limits of Moran's Autocorrelation Index for Raster Class Maps". Computers, Environment and Urban Systems, 31(3), 362-371.

Stoletov, V.N., Kon, I.S., Zamaşin, Y.A., Blyahman, L.S., Poşatayev, V.V., \& Volkov, G.N. (1979), Toplum ve Gençlik. Çeviren: Şükrü Keleş, Konuk Yayınları, İstanbul.

Şahin, S. (2018), Geçmiş, Günümüz ve Gelecekte Nüfus Gerçeği. Pegem Atıf İndeksi, 001-216.

Tobler, W. R. (1970), "A Computer Movie Simulating Urban Growth in The Detroit Region". Economic Geography, 46(1), 234-240.

TUIK, (2018), Adrese Dayalı Nüfus Kayıt Sistemi. Metaveri. http://tuik.gov.tr/PreTablo.do?alt id=1059

TUIK, (2019), ABPRS statistics. metaveri. http://tuik.gov.tr/PreTablo.do?alt id=1059

TUIK, (2019), Adrese Dayalı Nüfus Kayıt Sistemi. Metaveri. http://tuik.gov.tr/PreTablo.do?alt id=1059

TUIK, (2019), Analitik Çerçeve, Kapsam, Tanımlar ve Sınıflandırmalar. http://www.tuik.gov.tr/PreTablo.do?alt id=1047

TUIK, (2019), Analitik Çerçeve, Kapsam, Tanımlar ve Sınıflandırmalar. http://www.tuik.gov.tr/PreTablo.do?alt id=1059

Tung, R. L. (1984), "Strategic Management of Human Resources In The Multinational Enterprise". Human Resource Management, 23(2), 129-143.

Turner, M. G., Gardner, R. H., and O'neill, R. V. (2001). Landscape Ecology in Theoryand Practice (Vol. 401). New York: Springer.

UNCTAD, (2018), E-Handbook of Statistics. United Nations Conference on Tradeand Development.

UNITED NATIONS Population Division, (2001), World Populations Prospects. The 2000 Revision, Highlights, Population Division Department of Economicand Social Affairs United Nations, New York.

US CENSUS, (2011), Age and Sex Composition: 2010. C2010BR-03, US Department of Commerce, Economics and Statistics Administration, US Census Bureau.

Vitalis, S., Arroyo Ohori, K., and Stoter, J. (2020). "CityJSON in QGIS: Development of an opensource plugin". Transactions in GIS.

Wang, X., Chen, Y., Liu, B., Shen, Y., and Sun, H. (2013), “A Total Factor Productivity Measure for The Construction Industry and Analysis of Its Spatial Difference: A Case Study In China". Construction Management and Economics, 31(10), 1059-1071.

Ward, M. D., and Gleditsch, K. S. (2018), Spatial Regression Models (Vol. 155). Sage Publications. 